\title{
SIRKULASI PERGERAKAN PADA GEDUNG REKTORAT UNIVERSITAS BENGKULU
}

Movement Circulation in the Rectorate Building Bengkulu University

\author{
Dwi Oktavallyan Saputri \\ Program Studi Arsitektur, Fakultas Teknik, Universitas Bengkulu \\ JI. W.R. Supratman, Kandang Limun, Kota Bengkulu \\ dwi.oktavallyan@unib.ac.id
}

\begin{abstract}
Abstrak
Gedung Rektorat merupakan salah satu gedung yang memiliki peranan penting dalam menjalankan kegiatan di lingkungan Universitas baik kegiatan yang akan direncanakan, dilaksanakan, maupun dievaluasi. Sirkulasi pergerakan pada suatu bangunan memiliki banyak fungsi dalam menjalankan perannya, sehingga sedemikian rupa dirancang agar aktivitas atau kegiatan berjalan dengan baik. Dengan latar belakang tersebut, maka tujuan penelitian ini adalah untuk mengetahui pola sirkulasi pergerakan pada Gedung Rektorat Universitas Bengkulu. Metode penelitian yang dilakukan bersifat deskriptif kualitatif, yaitu mendeskripsikan hasil pengamatan yang dilakukan melalui observasi lapangan berdasarkan teori sirkulasi yang dilakukan secara sistematis dan aktual. Berdasarkan hasil penelitian, ditemukan bahwa Gedung Rektorat menerapkan beberapa pola sirkulasi pergerakan dalam ruang yang berrtujuan untuk mencapai suatu tujuan. Hasil penelitian ini diharapkan dapat menjadi masukan dan guideline dalam pengembangan dalam mendesain sirkulasi pergerakan dalam ruang pada Gedung Rektorat Universitas.
\end{abstract}

Kata kunci: Pergerakan, Ruang, Rektorat, Sirkulasi.

\begin{abstract}
The Rectorate Building is one of those that have important roles in carrying out activities at a university campus, both activities that will be planned, implemented, or evaluated. The circulation of movement in a building has many functions in carrying out its role so that its appearance is designed so that the activity or activity runs well. With this background, the purpose of this study is to see the movement pattern of the Bengkulu University Rectorate Building. The research method is descriptive qualitative in nature, which describes the results of observations made through field observations based on systematic and actual theory. Based on the research results, it was found that the Rectorate Building implements several movement patterns in space that aim to achieve a goal. The results of the research are expected to become input and guidance in developing circulation in the movement in space in the University Rectorate Building.
\end{abstract}

Keywords: Movement, Space, Rectorate Building, Sirculation.

\section{Pendahuluan}

Gedung Rektorat merupakan salah satu gedung yang keberadaannya memiliki peranan penting di suatu Universitas. Selain menjadi gedung kerja pimpinan universitas dan jajarannya, gedung rektorat Universitas Bengkulu juga memiliki banyak fungsi seperti pelayanan mahasiswa, ruang kepegawaian, ruang keuangan, ruang rapat utama, dan lain sebagainya. Dengan banyaknya fungsi, maka timbul berbagai macam aktivitas yang terdapat di gedung tersebut. Aktivitas yang timbul akan membutuhkan suatu sirkulasi yang beranekaragam. 
Sirkulasi merupakan hal penting yang harus diperhatikan dalam suatu bangunan yang memiliki berbagai macam aktivitas. Seperti halnya sirkulasi dalam pencapaian gedung maupun suatu ruang di gedung rektorat Universitas Bengkulu, merupakan hal dasar yang harus dirancang sedemikian rupa agar dapat memberikan suatu kemudahan bagi para pengguna. Komponen suatu sirkulasi yang terdapat di bangunan akan mempengaruhi efektivitas pergerakan didalam suatu ruang. Sebagaimana yang dikemukakan (Syoufa, 2014) bahwa pola sirkulasi sangat menetukan keberhasilan dari suatu fungsi ruang atau bangunan dan pola susunan ruang juga mempengaruhi bentuk sirkulasi.

Sirkulasi merupakan pergerakan dalam suatu kegiatan dalam ruang baik secara vertical maupun horizontal. Komponen pola sirkulasi dalam ruang sebagai unsur yang mempengaruhi bentuk ruang menurut Francis D.K Ching (2000) antara lain, pencapaian bangunan, jalan masuk ke dalam bangunan, konfigurasi jalan, hubungan jalan-ruang, bentuk ruang sirkulasi.

McLean (1993) juga mengungkapkan bahwa terdapat beberpa tipe pola sirkulasi yang biasa diterapkan dalam bangunan publik, antara lain pola sirkulasi langung (direct plan), pola sirkulasi terbuka (open plan), pola sirkulasi berputar (radial plan), dan pola sirkulasi acak (random plan).

Gedung Rektorat Universitas Bengkulu yang memiliki 4 lantai dengan luasan yang cukup besar dan mempunyai sirkulasi yang terlihat cukup beranekaragam. Berbagai macam aktivitas di gedung rektorat terlihat dari berbagai pergerakan yang dilakukan di gedung tersebut. Dengan latar belakang tersebut, maka peneliti tertarik untuk melihat, mengetahui, dan mengidentifikasi pola sirkulasi pergerakan dalam ruang pada gedung rektorat Universitas Bengkulu.

\section{Metode}

Penelitian ini mengunakan pendekatan deskriptif kualitatif yaitu melakukan observasi atau pengamatan langsung ke lapangan berdasarkan kajian teori yang telah dilakukan. Teknik pengumpulan data dilakukan dengan melakukan pengamatan langsung di Gedung Rektorat Universitas Bengkulu. Pengamatan akan dilakukan di lantai 1, lantai 2, lantai 3 dan lantai 4 Gedung Rektorat Universitas Bengkulu. Metode ini juga digunakan (Syoufa, 2014) dengan deskriptif analisis yang dapat mengurai secara detail dalam menganalisis pola sirkulasi. Pengamatan berfokus pada bagaimana pola pencapaian bangunan, jalan masuk ke dalam bangunan, konfigurasi jalan, hubungan jalan-ruang, bentuk ruang sirkulasi dan pola sirkulasi Gedung Rektorat Universitas Bengkulu.

\section{Tabel 1: Jenis data primer yang dikumpulkan untuk sirkulasi pergerakan dalam ruang pada Gedung Rektorat Universitas Bengkulu}

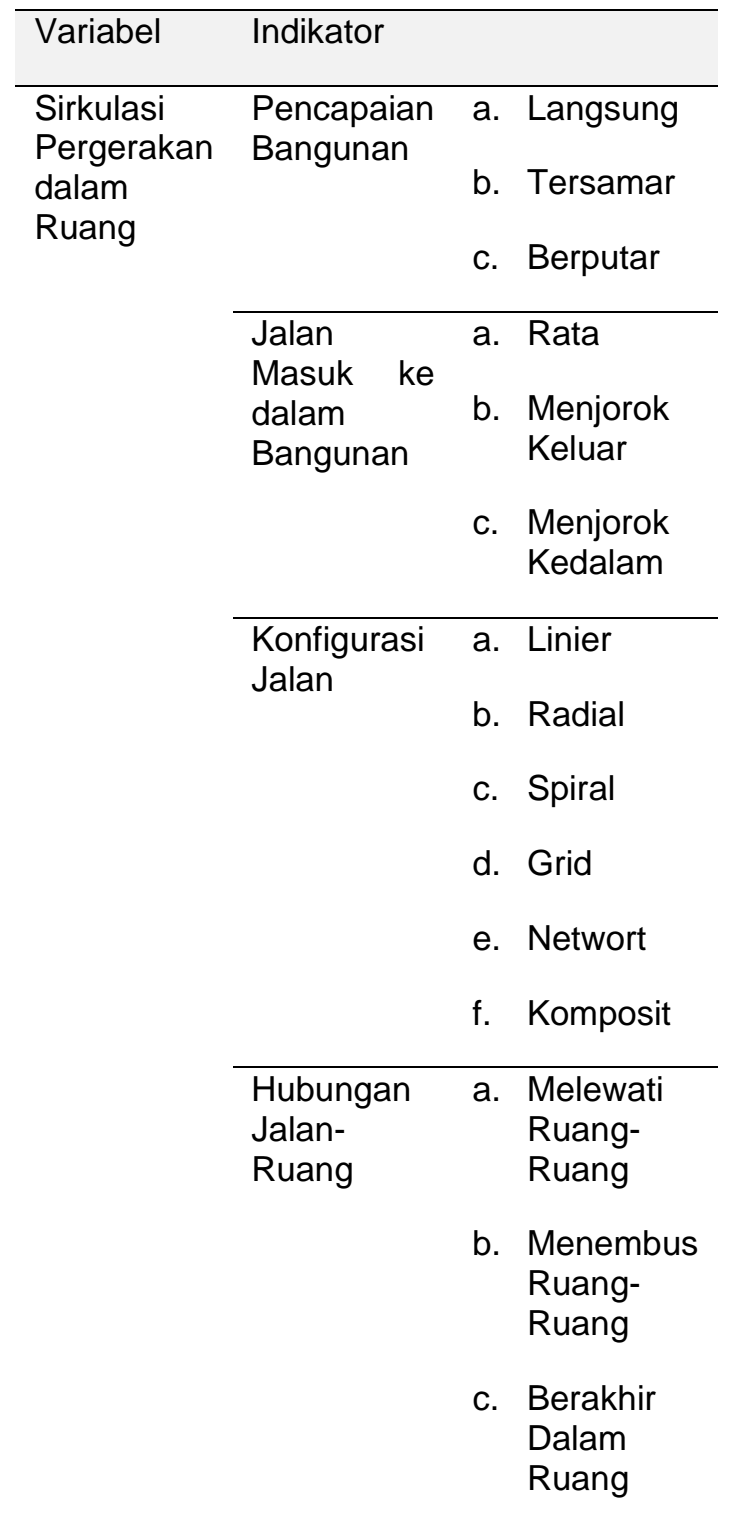




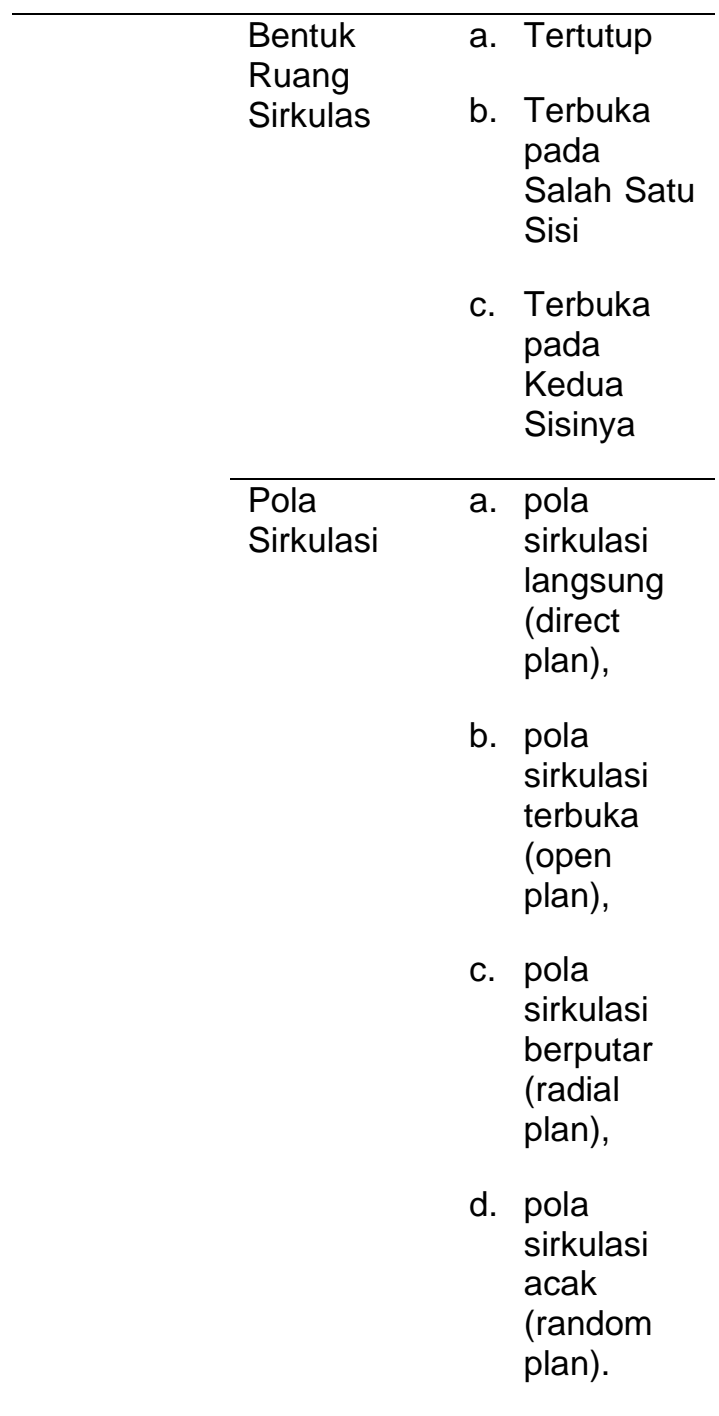

(Sumber: simpulan dari beberapa literatur, 2019)

\section{Kajian Teori}

Sirkulasi merupakan pergerakan dalam suatu kegiatan baik secara vertical maupun horizontal. Berikut adalah komponen dari sirkulasi dalam ruang sebagai unsur yang mempengaruhi tentang ruang bangunan menurut (2000) antara lain, pencapaian bangunan terdiri dari pencapaian lansung, tersamar, dan berputar, jalan masuk ke dalam bangunan terdiri dari rata, menjorok keluar, dan menjorok kedalam, konfigurasi jalan yang terdiri dari linier, radial, spiral, grid, dan network, hubungan jalan-ruang yang terdiri dari melewati ruang-ruang, menembus ruang-ruang, dan berakhir dalam ruang, dan bentuk ruang sirkulasi yang terdiri atas tertutup, terbuka pada salah satu sisi dan terbuka pada kedua sisinya.

Menurut Peraturan Menteri Pekerjaan Umum Dan Perumahan Rakyat Republik Indonesia Nomor 14/PRT/M/2017 Tentang Persyaratan Kemudahan Bangunan Gedung, dalam memperoleh kenyamanan dalm ruang beberapa hal yang harus dipertimbangkan fungsi ruang, aksesibilitas ruang, dan jumlah pengguna dan perabot/peralatan di dalam bangunan gedung, desain sirkulasi antarruang horizontal dan vertikal; dan faktor keselamatan dan kesehatan.

Beberapa pola sirkulasi pengguna yang dikemukakan oleh McLean (1993) antara lain, pola sirkulasi langsung (direct plan), pola sirkulasi terbuka (open plan), pola sirkulasi berputar (radial plan), dan pola sirkulasi acak (random plan). Pola sirkulasi tersebut menurut Wulandari (2012) ini memiliki kekurangan dan kelebihannya masing-masing. Sebagai contoh, pola sirkulasi langsung merupakan pola sirkulasi yang sederhana dan hanya memberikan pilihan jalan yang terbatas kepada pengguna untuk mencapai langsung ke tujuannya. sedangkan pola acak merupakan pola sirkulasi yang memberikan berbagai alternatif kepada penggunanya untuk mencapai suatu tujuan.

Pynkyawati (2014) telah melakukan penelitian mengenai efesiensi desain sirkulasi pada fungsi bangunan mall dan hotel di Bandung. Penelitian ini menganalisis berdasarkan teori dan kondisi lapangan, dan Pynkyawati (2014) menyimpulkan bangunan Mall dan Hotel BTC dirancang untuk memberikan kenyamanan pengguna sesuai dengan fungsinya masing-masing dilihat dari jarak dan waktu pencapaian antar kedua bangunan tersebut. Bentuk ruang dalam bangunan, zona fungsi ruang, dan pola sirkulasi juga mempengaruhi tingkat efektifitas antara dua fungsi bangunan Mall dan Hotel. Pada bangunan Mall dan Hotel, hasil pengamatannya bahwa bentuk ruang sirkulasi fungsi yang berbeda membentuk ruang sirkulasi tertutup. Terlihat dari koridor yang dibentuk oleh kios-kios pada mall dan 
dinding masif pada kedua sisinya pada hotel.

\section{Hasil dan Pembahasan}

\section{Pencapaian Bangunan}

Gedung rektorat memiliki dua jalur main entrance ke dalam bangunan yaitu di pintu utara dan selatan bangunan dan side entrance yaitu sebelah barat dan timur bangunan. Main entrance yang terdapat di utara dan selatan merupakan jenis pencapaian tersamar, terlihat dari jalur pencapaian yang terhambat dengan adanya pembatas sebagai penghambat sirkulasi. Sehingga pencapaiannya menjadi tersamar dan memperpanjang jalur pencapaian. Sedangkan untuk side entrance yang terdapat di timur dan barat menerapkan desain pencapaian langsung dikarenakan tidak adanya penghambat sirkulasi.

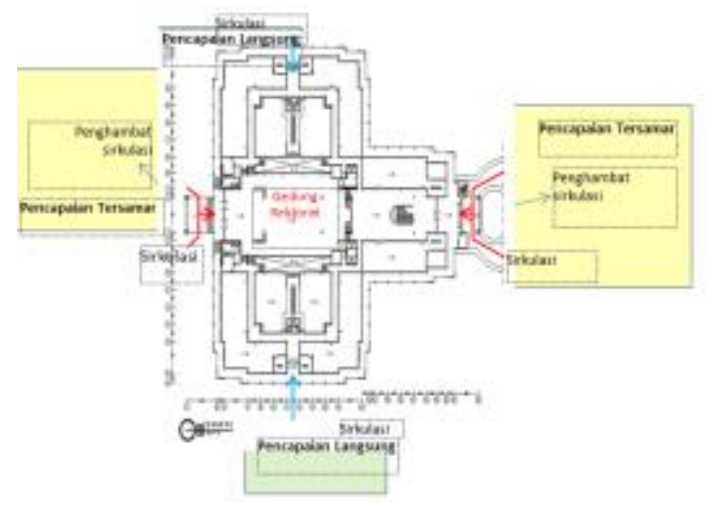

\section{Gambar 1: Pencapaian Gedung Rektorat Universitas Bengkulu (Sumber: Penulis, 2019)}

Jalan Masuk ke dalam Bangunan

Main entrance yang terdapat di utara dan selatan memiliki jalan masuk ke dalam bangunan yang menjorok keluar. Jalan masuk yang menjorok ke luar membentuk sebuah ruang transisi, menunjukkan fungsinya sebagai pencapaian dan memberikan pernaungan di atasnya. Sedangkan untuk side entrance yang terdapat di timur dan barat menerapkan jalan masuk yang menjorok ke dalam. Jalan masuk yang menjorok ke dalam memberikan perlindungan dan menerima sebagian ruang luar menjadi bagian dari bangunan dindingnya sehingga terlihat tersamar.
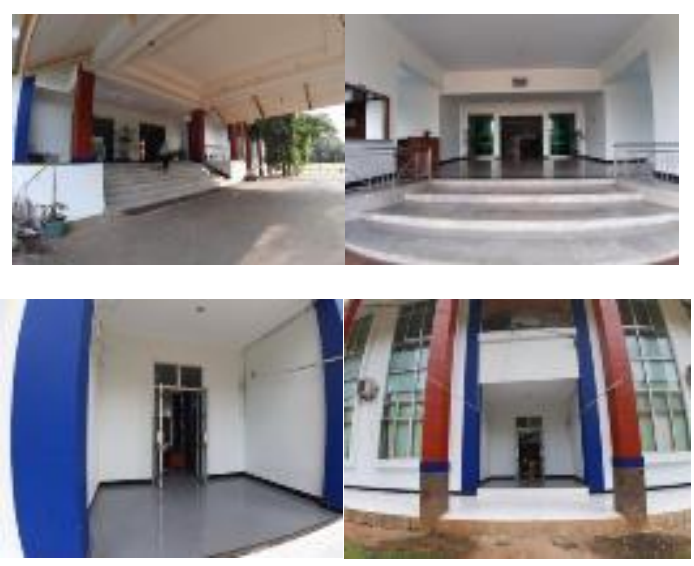

Gambar 2: Jalan Masuk Main Entrance dan Side Entrance

(Sumber: Penulis, 2019)

Menurut lokasinya, baik main entrance maupun side entrance meletakkan pintu masuk terpusat di dalam bidang depan bangunan. Letak pintu masuk pada Gedung Rektorat ini memiliki garis yang simetris dan menciptakan keadaan simetris terhadap bangunan itu sendiri. Posisi sebuah pintu masuk relatif akan menentukan konfigurasi jalur serta pola aktivitas di dalam ruang tersebut.

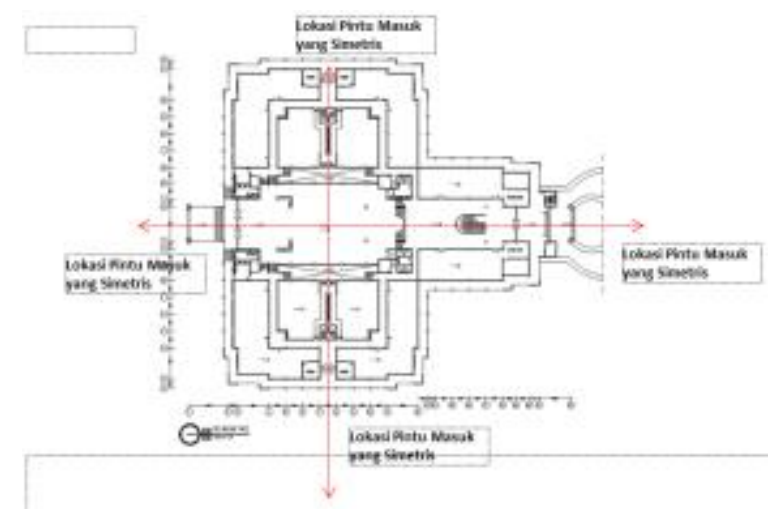

\section{Konfigurasi Jalan}

Konfigurasi jalan merupakan suatu alur pergerakan sirkulasi bagi para penguna. Sebuah desain terkadang menganut beberapa konfigurasi jalan untuk dapat menjalankan fungsi desain itu sendiri. Berikut konfigurasi jalan di setiap lantai 
pada Gedung Rektorat Universitas Bengkulu.
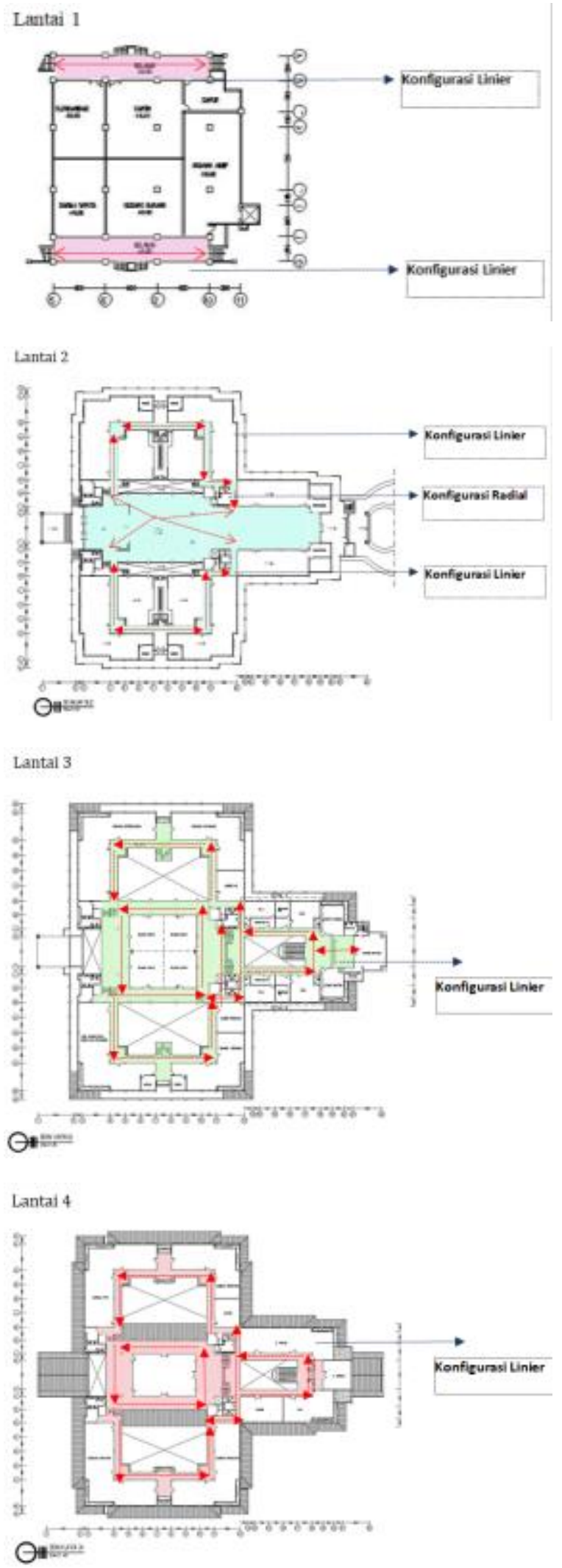

Gambar 4: Konfigurasi Jalan Lantai 1-4 Gedung Rektorat Universitas Bengkulu (Sumber: Penulis, 2019)
Pada lantai 1 Gedung Rektorat Universitas Bengkulu menerapkan konfigurasi linier. Konfigurasi linier ini terlihat dari jalur pergerakan sirkulasi yang merupakan jalan lurus berupa selasar. Pada lantai 2 Gedung Rektorat Universitas Bengkulu menerapkan konfigurasi linier dan konfigurasi radial. Konfigurasi linier ini terlihat dari jalur pergerakan sirkulasi sebelah barat dan timur bangunan berupa selasar yang melengkung mengintari lantai 2. Konfigurasi radial terdapat di tengah bangunan karena merupakan sebuah titik pusat untuk memulai pergerakan yang berupa ruangan aula. Pada lantai 3 dan lantai 4 Gedung Rektorat Universitas Bengkulu menerapkan konfigurasi linier. Konfigurasi linier ini terlihat dari jalur pergerakan sirkulasi yang merupakan jalan lurus berupa selasar yang mengintari ruangan. Semua sirkulasi pergerakan pada bangunan Gedung Rektorat Universitas Bengkulu pada umumnya adalah berbentuk linier. Jalan yang lurus dapat menjadi suatu unsur utama yang mengorganisir deretan ruang-ruang di dalam suatu bangunan.

\section{Hubungan Jalan Ruang}

Hubungan jalan ruang merupakan suatu alur pergerakan sirkulasi untuk mencapai suatu tujuan dalam pencapaian ruangan bagi para penguna. Jalan dengan ruang-ruang yang dihubungkan dalam beberapa skema, antara lain yaitu melewati ruang-ruang, menembus ruang-ruang, dan berakhir dalam ruang. Berikut hubungan jalan ruang di setiap lantai pada Gedung Rektorat Universitas Bengkulu.

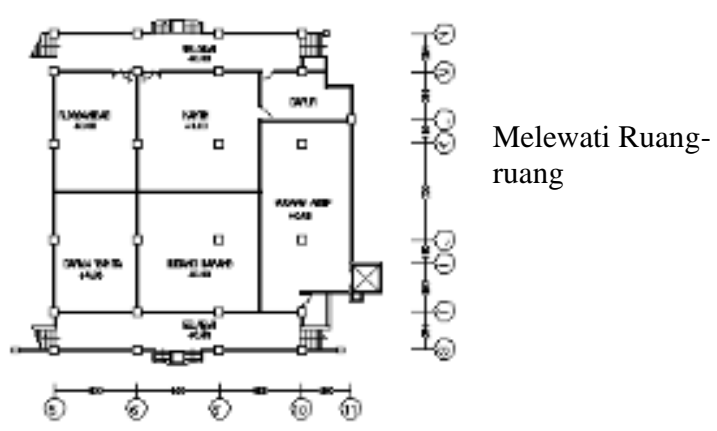



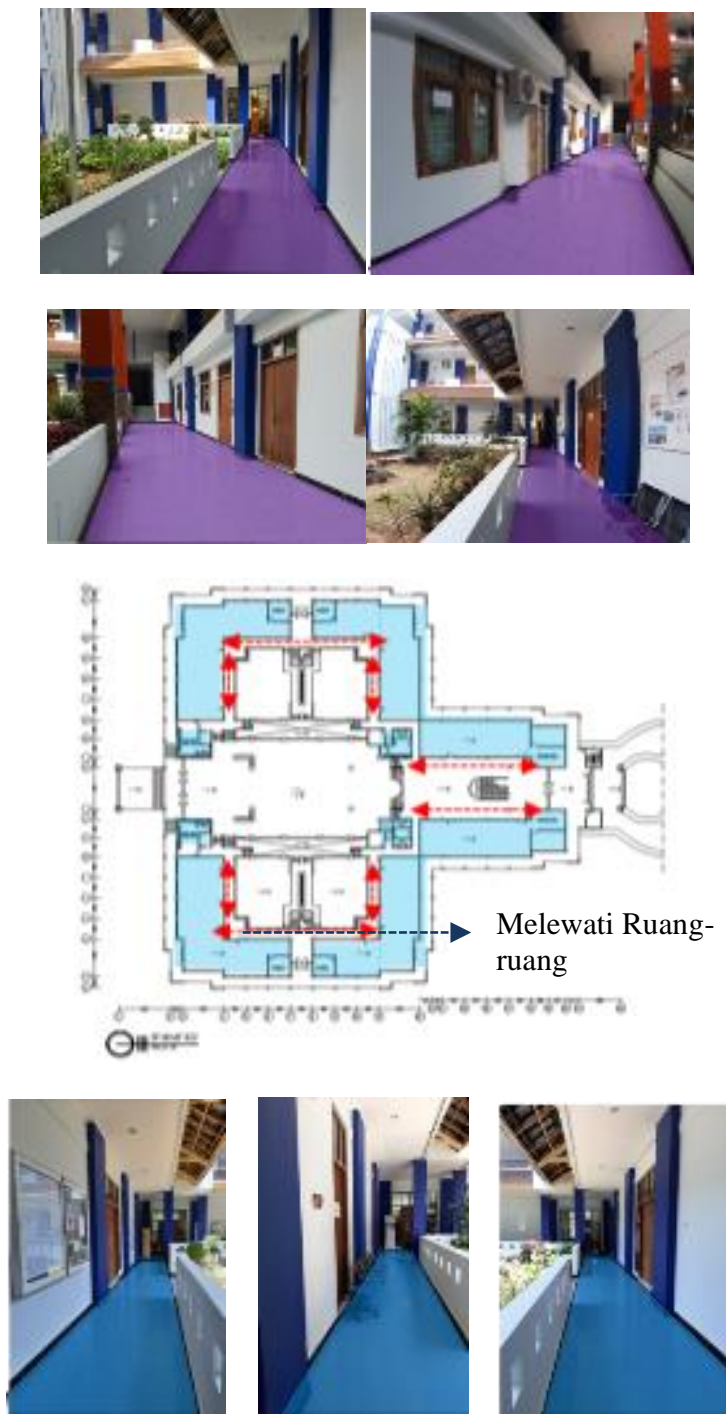

Gambar 5: Hubungan Jalan Ruangi 1-2 Gedung Rektorat Universitas Bengkulu (Sumber: Penulis, 2019)

Pada lantai 1 dan lantai 2 Gedung Rektorat Universitas Bengkulu menerapkan hubungan jalan ruang dengan melewati ruang-ruang. Hubungan jalan ruang dengan melewati ruang-ruang berupa ruang-ruang yang berfungsi sebagai kantor atau ruang kerja.

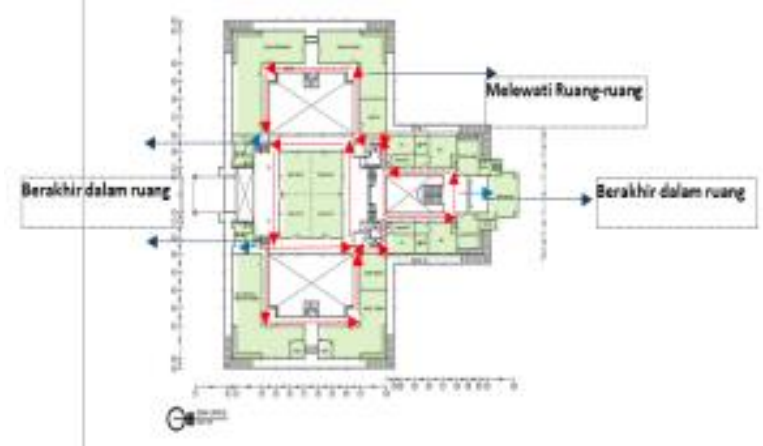

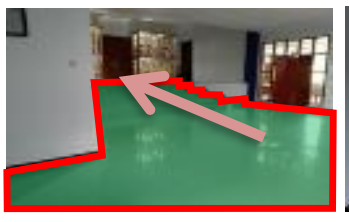
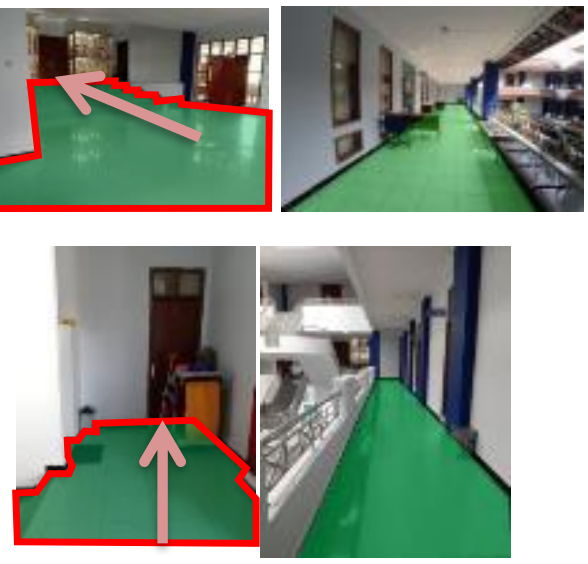

Gambar 6: Hubungan Jalan Ruang 3 Gedung Rektorat Universitas Bengkulu (Sumber: Penulis, 2019)

Pada lantai 3 Gedung Rektorat Universitas Bengkulu menerapkan hubungan jalan ruang dengan melewati ruang-ruang. Hubungan jalan ruang dengan melewati ruang-ruang berupa ruang-ruang yang berfungsi sebagai ruang kantor. Selain itu dilantai 3 juga menerapkan hubungan jalan ruang dengan berakhir dalam ruang. Sirkulasi ini terdapat di utara dan selatan bangunan yaitu pada sisi selatan berakhir pada ruangan kamar mandi/wc dan pada sisi utara berakhir pada ruangan Rektor Unversitas Bengkulu.
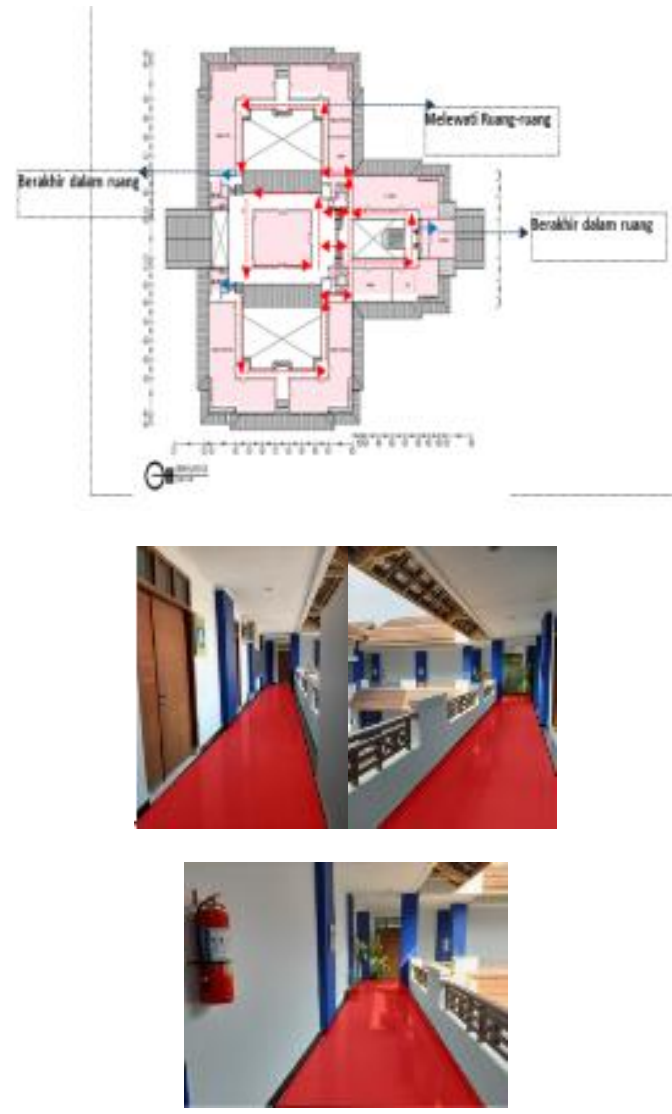

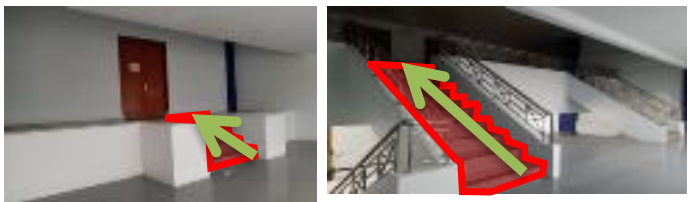

Gambar 7: Hubungan Jalan Ruang Lantai 4 Gedung Rektorat Universitas Bengkulu

(Sumber: Penulis, 2019)

Pada lantai 4 Gedung Rektorat Universitas Bengkulu menerapkan hubugan jalan ruang dengan melewati ruang-ruang. Hubugan jalan ruang dengan melewati ruang-ruang berupa ruang-ruang yang berfungsi sebagai ruang kantor. Selain itu dilantai 4 juga menerapkan hubungan jalan ruang dengan berakhir dalam ruang. Sirkulasi ini terdapat di utara dan selatan bangunan yaitu pada sisi selatan berakhir pada ruangan kamar mandi/wc dan pada sisi utara berakhir pada ruangan rapat besar dan ruang proyek.

Untuk mencapai suatu tujuan dalam pencapaian ruangan, pengguna akan melewati suatu jalan dengan cara yang beragam. Jalan dengan ruang-ruang dihubungkan pada Gedung Rektorat Universitas Bengkulu menerapkan desain hubungan jalan melewati ruang-ruang dengan mempertahankan tiap-tiap ruang menjadi satu kesatuan dengan konfigurasi jalan yang fleksibel dan juga menerapkan hubungan jalan berakhir dalam ruang yang digunakan untuk mencapai dan memasuki secara fungsional atau melambangkan ruang-ruang yang penting. Sama halnya dengan penelitian (Pynkyawati, 2014) bahwa bentuk ruang sirkulasi yang terbentuk berdasarkan kebutuhan ruangnya masing-masing

\section{Bentuk Ruang Sirkulasi}

Sirkulasi merupakan suatu ruang yang berfungsi untuk menghubungkan ruangan satu dengan ruangan lainnya. Bentuk ruang sirklasi pun beragam, seperti bentuk ruang sirkulasi tertutup, bentuk ruang sirkulasi terbuka pada salah satu sisi, dan bentuk ruang sirkulasi terbuka pada kesua sisinya. Berikut bentuk ruang sirkulasi pada Gedung Rektorat Universitas Bengkulu.
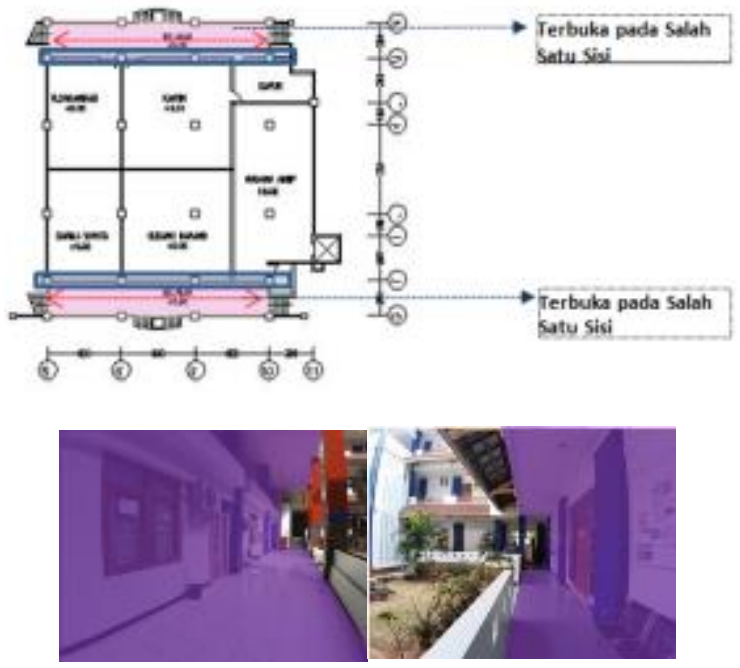

Gambar 8: Bentuk Ruang Sirkulasi Lantai 1 Gedung Rektorat Universitas Bengkulu (Sumber: Penulis, 2019)

Pada lantai 1 Gedung Rektorat Universitas Bengkulu menerapkan bentuk ruang sirkulasi terbuka pada salah satu sisi. Terlihat pada gambar diatas bahwa salah satu sisi ruang sirkulasi terbuka yang menghadap ke taman sedangkan salah satu sisi lainnya merupakan ruangan pada gedung.
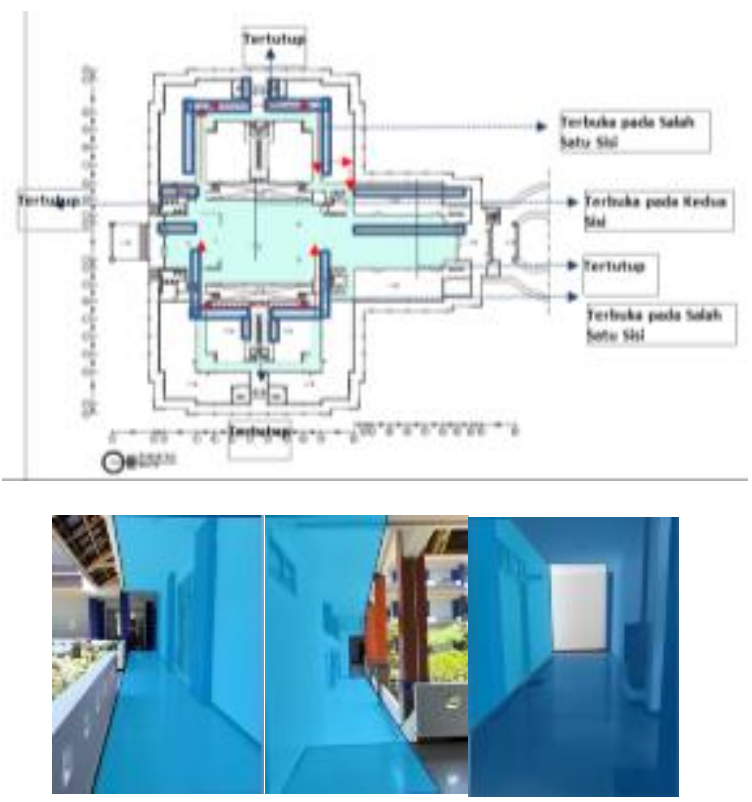

Gambar 9: Bentuk Ruang Sirkulasi Lantai 2 Gedung Rektorat Universitas Bengkulu (Sumber: Penulis, 2019)

Pada lantai 2 Gedung Rektorat Universitas Bengkulu menerapkan bentuk ruang sirkulasi terbuka pada salah satu sisi. Terlihat pada gambar diatas bahwa salah satu sisi ruang sirkulasi terbuka yang 
menghadap ke taman sedangkan salah satu sisi lainnya merupakan ruangan pada gedung. Dibeberapa titik juga menerapkan ruang sirkulasi yang tertutup yaitu pada ruang kamar mandi/wc dan ruangan yang berdekatan dengan main entrance. Pada aula yang merupakan titik pusat sirkulasi menerapkan bentuk ruang yang kedua sisinya terbuka.
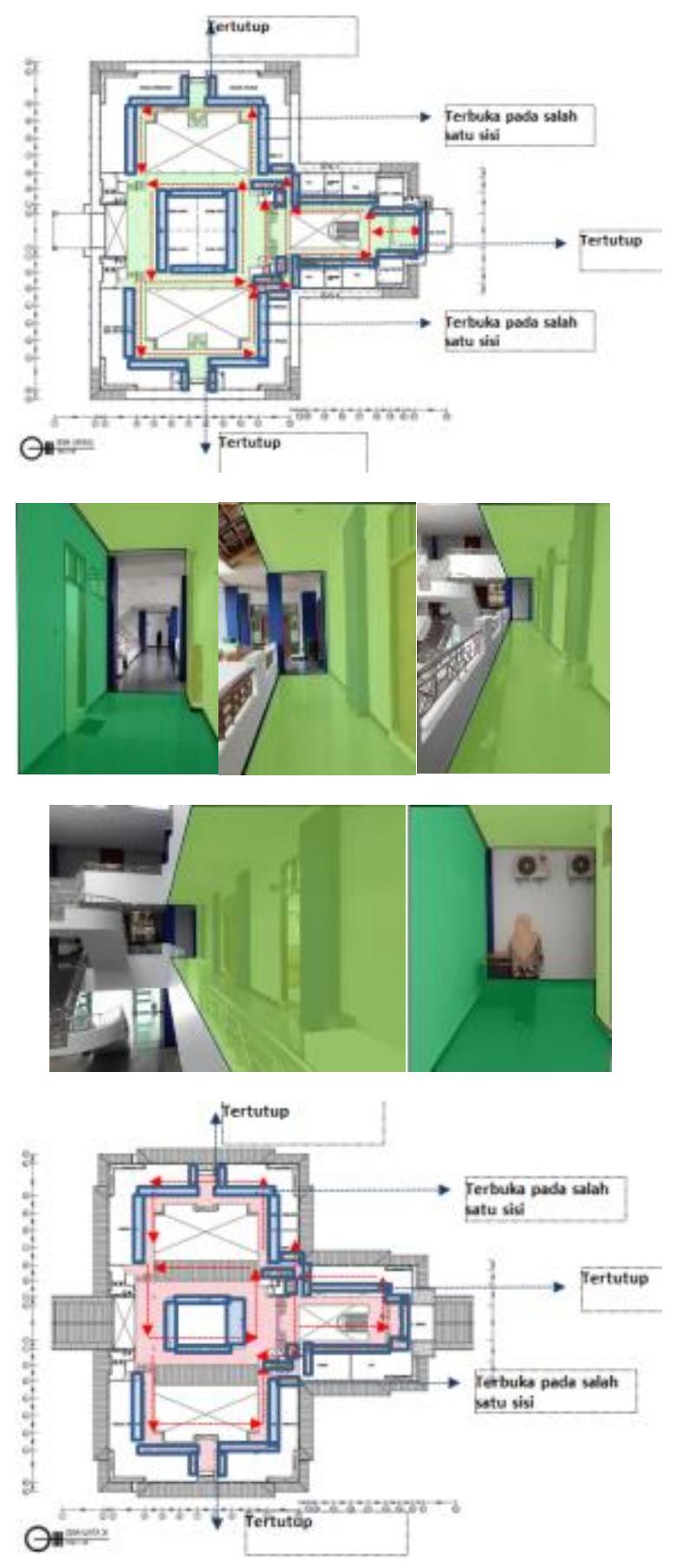

TERAKREDITASI : 36/E/KPT/2019

ISSN cetak 1410-6094 | ISSN online 2460-6367
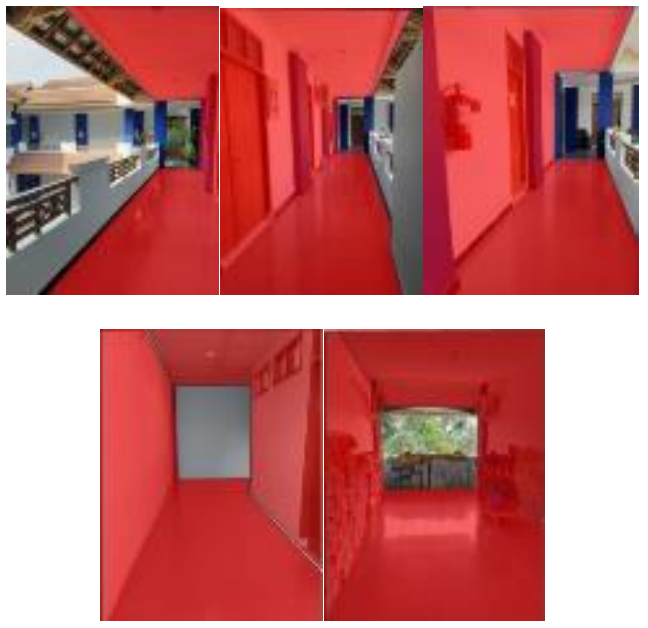

Gambar 10: Bentuk Ruang Sirkulasi Lantai 3 dan 4 Gedung Rektorat Universitas Bengkulu

(Sumber: Penulis, 2019)

Pada lantai 3 dan 4 Gedung Rektorat Universitas Bengkulu memiliki bentuk denah yang tipkal dan menerapkan bentuk ruang sirkulasi terbuka pada salah satu sisi. Terlihat pada gambar diatas bahwa salah satu sisi ruang sirkulasi terbuka yang menghadap ke taman sedangkan salah satu sisi lainnya merupakan ruangan pada gedung. Dibeberapa titik juga menerapkan ruang sirkulasi yang tertutup yaitu pada ruang kamar mandi/wc dan ruangan yang berdekatan dengan main entrance.

Pada umumnya gedung Rektorat Universitas Bengkulu menerapkan bentuk ruang sirkulasi yang terbuka pada salah satu sisi. Bentuk ruang sirkulasi terbuka pada salah satu sisi yang memberikan kontinuitas visual / ruang dengan ruangruang yang dihubungkannya dan memberikan pencahayaan dan penghawaan yang baik. Pada beberapa titik bangunan menerapkan bentuk ruang sirkulasi tertutup. Bentuk ruang sirkulasi yang tertutup ini membentuk koridor dan menimbulkan kesan privat.

\section{Pola Sirkulasi}

Pola sirkulasi menurut Wulandari (2012) ini memiliki kekurangan dan kelebihan sendiri-sendiri, seperti pola sirkulasi langsung sangatlah sederhana dan hanya memberikan pilihan jalan yang terbatas kepada pengunjung. Berbeda dengan pola acak, pola sirkulasi memberikan ragam alternatif arah yang 
membuat pengunjung-pengunjung seakanakan tidak terkontrol. Pola sirkulasi terbuka sangat baik digunakan jika perancang ingin agar pengunjung dapat melihat keseluruhan ruang secara langsung seperti ruang pamer lukisan, misalnya. Walaupun kekurangannya adalah pengunjung kehilangan rasa keingintahuan dan eksplorasi karena semua sudah terlihat.

Pada gedung Rektorat Universitas Bengkulu pada lantai 1 hingga lantai 4 memiliki pola direct plan yang terlihat dari pola sirkulasi yang mengarahkan langsung ker tujuan tanpa memiliki alternatif atau pilihan jalan yang terkesan bebas. Pola direct plan ini efektif untuk gedung perkantoran termasuk Gedung Rektorat. Azhima, 2018 juga mengungkapkan sirkulasi yang bersifat langsung/direct memiliki arah atau tujuan yang langsung dengan perjalanan yang lebih singkat sebagaimana gedung ini yang memiliki fungsi sebagai fasilitas pelayanan. Hanya terdapat pada lantai 2 yang memiliki pola sirkulasi Open plan atau sirkulasi yang para penggunanya dapat bergerak bebas. Hal ini sesuai dengan fungsi ruang tersebut yaitu ruang terbukan yang dapat digunakan sebagai ruang komunal, atau yang sekarang difungsikan untuk ruang ibadah.
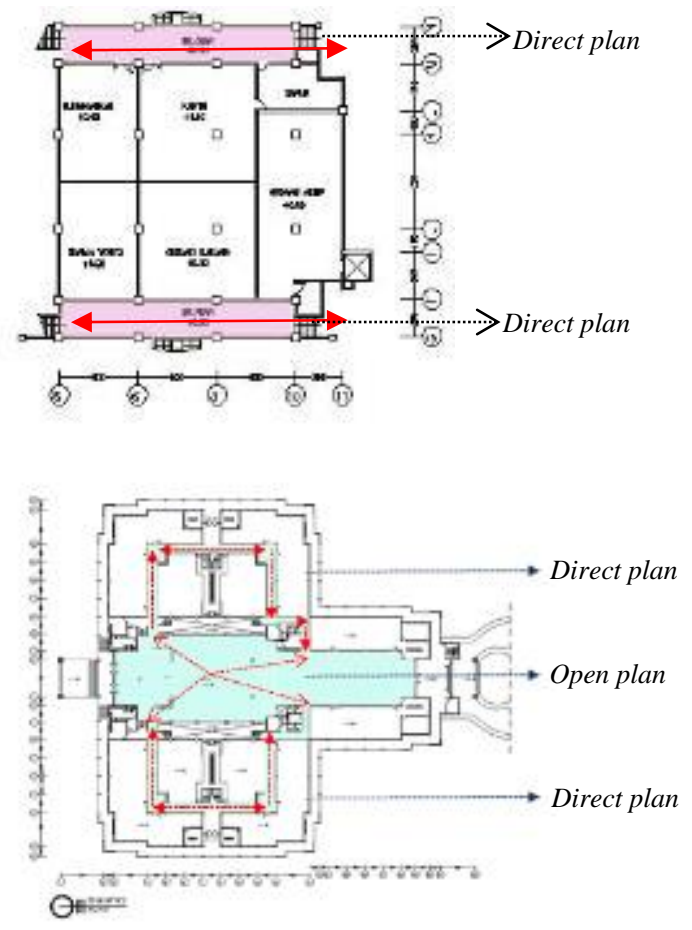

TERAKREDITASI : 36/E/KPT/2019

ISSN cetak 1410-6094 | ISSN online 2460-6367

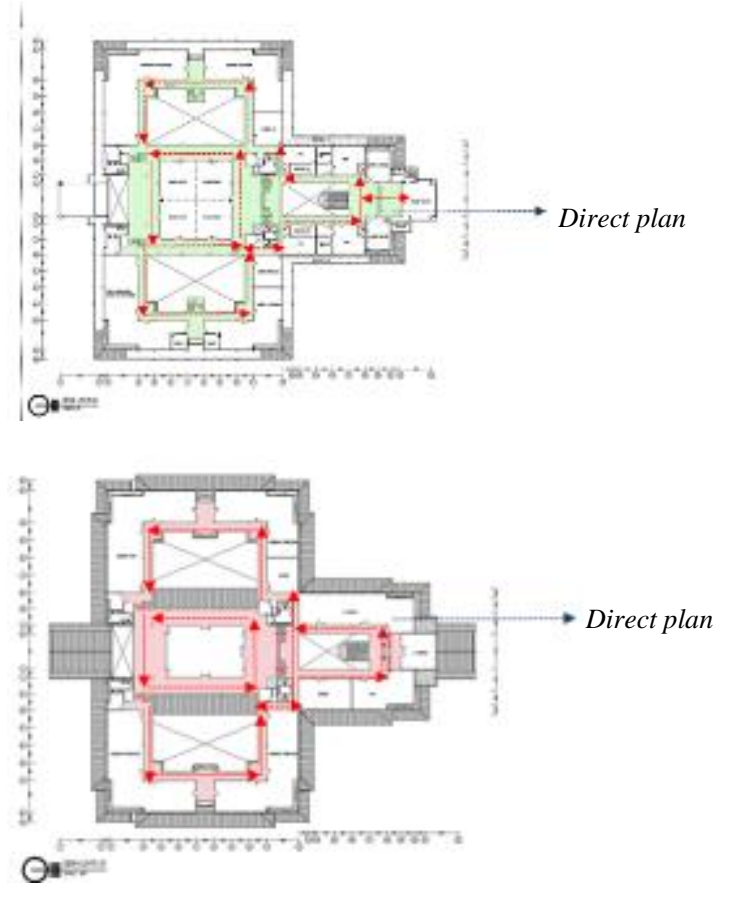

Gambar 11: Bentuk Ruang Sirkulasi Lantai 1-4 Gedung Rektorat Universitas Bengkulu (Sumber: Penulis, 2019)

\section{Kesimpulan dan Saran}

\section{Kesimpulan}

Berdasarkan hasil penelitian, dapat dijabarkan bahwa pada pencapaian gedung memiliki jenis pencapaian tersamar dengan adanya pembatas sebagai penghambat sirkulasi sebagai main entarnce dan pencapaian langsung dikarenakan tidak adanya penghambat sirkulasi sebagai side entarnce. Main entrance dan side entrance memiliki bentuk simetris yang mempermudah penggunanya dalam mencapai bangunan. Jalan masuk yang menjorok ke luar membentuk sebuah ruang transisi juga menunjukkan fungsinya sebagai pencapaian dan memberikan pernaungan di atasnya. Pada konfigurasi bangunan menerapkan konfugurasi linier yang mengorganisir deretan ruang-ruangan perkantoran sehingga konfigurasi yang linier membuat jenis hubungan jalan ruang yang diterapkan hampir semua adalah melewati ruang-ruang. yang berfungsi sebagai kantor atau ruang kerja. Bentuk ruang sirkulasi di Gedung Rektorat ini hampir disemua bagian menerapkan sirkulasi terbuka pada salah satu sisi. 
Penerapan sirkulasi terbuka pada salah satu sisi bertujuan untuk mengoptimalkan pencahayaan alami yang dapat diterima. Dan pola sirkulasi direct plan ini diterapkan hampir disemua bagian karena efektif untuk gedung perkantoran termasuk Gedung Rektorat yang memiliki fungsi sebagai fasilitas pelayanan yang mengarahkan langsung ker tujuan tanpa memiliki alternatif atau pilihan jalan yang terkesan bebas. Dengan ini ditemukan bahwa Gedung Rektorat menerapkan beberapa desain sirkulasi pergerakan yang pada umumnya terdapat pada gedung perkantoran dengan banyak ruang atau fungsi dengan bentuk desain sirkualsi yang mempermudah dalam mencapai suatu tujuan dalam menjalankan fungsi gedung tersebut.

\section{Saran / Rekomendasi}

Saran untuk penelitian lebih lanjut adalah gedung rektorat merupakan gedung pelayanan sehingga perlu diperbaiki khususnya pada penerapan elemen sirkulasi. Penerapan elemen sirkulasi dibutuhkan bagi gedung ini untuk mempermudah para pengguna gedung, seperti penerapan panah/penunjuk arah pada titik-titik tertentu dan symbol yang dibutuhkan bagi para disabilitas khususnya.

Penggunaan text pada penamaan ruanganpun harus di buat sedemikian efektifif untuk memudahkan pengguna bangunan memperoleh informasi.

\section{Ucapan Terimakasih}

Terima kasih disampaikan kepada LPPM Universitas Bengkulu dan Fakultas Teknik Universitas Bengkulu yang telah membantu dalam melakukan penelitian ini dan segala bantuan lain yang telah diberikan untuk kelancaran penelitian ini.

\section{Daftar Pustaka}

Azhima, F., Hidayati, R. (2018). Pengaruh Penataan Massa Bangunan Terhadap Pola Aktivitas Santri (Studi Kasus Pondok Pesantren Islamic Centre Bin
Baz Putra Yogyakarta). Jurnal Sinektika, 16-22.

Ching, Francis D.K. (2000). Arsitektur: Bentuk, Ruang, dan Tatanan Edisi Kedua. Jakarta: Erlangga.

http://www.unib.ac.id

McLean, K. (1993). Planning for People in Museum Exhibitions. Washington: Association of Science-Technology Centers

Syoufa, Ade, Helen.H. (2014) Pengaruh Pola Sirkulasi Pusat Perbelanjaan Mal Terhadap Pola Penyebaran Pengunjung. Jurnal Desain Konstruksi. Vol 2(13) 46-57.

Peraturan Menteri Pekerjaan Umum Dan Perumahan Rakyat Republik Indonesia Nomor: 14/PRT/M/2017 Tentang Persyaratan Kemudahan Bangunan Gedung

Pynkyawati Theresia, Samsul. A, Eri. I, Leslye. Y, Amri. (2014) . Kajian Efisiensi Desain Sirkulasi pada Fungsi Bangunan Mall Dan Hotel BT, Jurnal Reka Karsa. Vol 2(1): 1-12.

Wulandari, Anak Agung Ayu. (2014). Dasar-Dasar Perencanaan Interior Museum. HUMANIORA. April Vol.5 No.1: 246-257 